\title{
HUMIDITY AND MOISTURE
}

$\mathrm{T}$ HE symposium on "Humidity and MoistureMeasurement and Control in Science and Industry" attracted more than 850 scientists and engineers from five continents to Washington, D.C., during May 20-23. The symposium was sponsored by the U.S. National Bureau of Standards and the U.S. Weather Bureau, both of which are agencies of the U.S. Department of Commerce, together with the Instrument Society of America, the American Meteorological Society, and the American Society of Heating, Refrigerating and Air-Conditioning Engineers. These five organizations joined in sponsoring the symposium because of their interest in humidity and moisture, ranging from the meteorologist's interest in humidity of the atmosphere to the engineer's concern with humidity in cryogenic materials.

The more than 230 papers presented in thirty-two sessions dealt with topics ranging from humidity standards and fundamentals, through means of measuring and controlling humidity and moisture, to specific applications. These applications varied from measurement of the humidity of air for meteorological purposes to determination of moisture in grain - an important factor in storage. of particular interest were papers on applications in biology and medicine, describing the use of controlled humidity in treatment and the relationship of symptoms to humidity-level.

Moisture has always been the essential, though often invisible, ingredient in most processes of science, industry and agriculture-in fact, virtually every field of human endeavour. To-day humidity measurements are being extended in two dimensions-to include more processes, and to obtain more accurate values. It is now sometimes necessary to know to an accuracy of a fraction of 1 per cent how much moisture is included in a eryogenic material, a refrigerant or a storage enclosure.

All five of the organizations sponsoring the symposium are concerned with problems of measuring and controlling humidity and moisture. Both the Weather Bureau and the American Meteorological Society deal with humidity measurements for weather prediction, including the recording and transmission of humidity data from unattended stations. The American Society of Heating, Refrigerating and Air-Conditioning Engineers is concerned with measurement and control of humidity not only for personal comfort but also in industrial and agricultural processes and in the preservation of materials. Members of the Instrument Society of America are interested in the design and applications of hygrometers, psychrometers, and other humidity transducers. Finally, the National Bureau of Standards is faced with the need for new techniques in measurement of humidity and for more accurate and easily used standards of humidity.

The symposium was opened on May 20 with a plenary session presided over by W. A. Wildhack, associate director of the National Bureau of Standards and chairman of the general committee of the symposium. The main address was delivered by Dr. J. H. Hollomon, assistant secretary of commerce for science and technology. Dr. Hollomon noted that man's advances in science and technology now permit him to exercise control over his environment, including humidity and moisture. He saw man's own abilities as a neglected or undeveloped natural resource, noting that the number of engineers who will graduate in the United States in 1963 is the same as five years ago. The remainder of the plenary session was devoted to papers on basic concepts and of general interest in the field of humidity. A second plenary session held later consisted of papers surveying the state of the hygrometry art in selected fields.
At a banquet held on the evening of May 21 the assembly of scientists was addressed by officers of the five sponsoring groups. J. H. Fox, president of the American Society of Heating, Refrigerating and Air-Conditioning Engineers, described the activities of his Society, emphasizing the research activities it supports, such as investigations of the effect of humidity on milk production and the habit. ability of survival shelters. He expressed the Society's concern that the number of students reading applied sciences is decreasing, although the number of college registrants is rising.

The American Meteorological Society was represented by its vice-president, Dr. Helmut E. Landsberg, who commented briefly on personalities and instruments prominent in the history of humidity measurement. The wide variety of indicating materials used in early hygrometers was a surprise even to those well versed in hygrometry.

The activities of the Instrument Society of America were noted by its president, Nathan Cohn, who also suggested that honour is due to the only American whose name has been given to a fundamental electrical unit. Mr. Cohn described Joseph Henry's concern that scientists be able to communicate and co-operate with each other and cited the Symposium as one which would have had Henry's approval.

F. W. Reichelderfer, chief of the U.S. Weather Bureau, discussed humidity as being of widespread interest as a factor in forming the world's weather. He described the World Meteorological Organization as a particularly effective means of transmitting useful meteorological data.

Dr. A. V. Astin, director of the U.S. National Bureau of Standards, noted the necessity that measurements made by all scientists and engineers be compatible and interchangeable. He emphasized the Bureau's concern with devising standard measurement techniques that can be applied at local levels.

\section{Fundamentals}

The sessions of the symposium devoted to fundamentals included papers and discussion on the fundamental laws. principles and relationships governing the behaviour of water vapour--gas mixtures, mainly moist air, and on the properties of water as basic to instruments and processes involving humidity. With the inereasing demand for more accurate humidity measurements, a need has arisen for theoretical foundations provided by real gas behaviour, rather than an assumed ideal gas. The papers which were presented provided important new information on real gas behaviour of mixtures of which water vapour is an important constituent, and on the transport and thermodynamic properties of moist air.

\section{Humidity Measuring Instruments}

The water-vapour content of gases is measured by a wide diversity of instruments, the methods spanning a broad realm in the fields of physics, chemistry and engineering. A major portion of the symposium was devoted to important methods used in modern hygrometry.

Three sessions were concerned entirely with electric hygrometry, which is utilized in many areas of science and industry because of its high sensitivity, its use of small sensors, and its adaptability to recording or remote indication. Among the sensors considered were those based on electrolytic solutions, carbon films, polyelectroly. tic films, ceramics, thin vacuum deposited salt films, oxide films and plastics. 
Psychrometry has a history which goes back to the early part of the nineteenth century. Still a major method for measuring the humidity of air, it finds extensive applica. tion in meteorology, air conditioning, and industry. Both theoretical and experimental papers treated the use of psychrometers under such unusual conditions as temporatures below freezing and hot, arid atmospheres. Other electric hygrometric instruments that were described included those using the Peltier effect, spoctroscopic mothods, infra-red and ultra-violet radiation, and, operating in another area of the spoctrum, microwave refractometers and hygrometers.

In dew-point and frost-point hygromotors humidity is measured as the temperature at which dew or frost is dэposited on a cooled surface, usually a highly polished mirror. Theoretical aspects of this method of measurement and improved versions of dew-point and frost-point instruments were deseribed. Considerable interest was shown in hygrometers utilizing the Peltier offect to cool the mirror and others providing high accuracy with automatic operation and continuous recording.

Unusual measuring methods were also described, among them a chemical technique for measurements of low water-vapour pressure. Another paper described an instrument detecting the heat generated with water absorption by a desiccant and still others the design of cells which absorb and electrolyse water vapour for measurement of humidity as a function of the electrolysing current. Critical discussions of the advantages and shortcomings of thermal conductivity methods and hair hygrometers were presented in review papers.

\section{Moisture Measurements}

The latest advances in the art of measuring moisture in solids and liquids also had a place in the symposium, since moisture critically affects the behaviour of many materials. A session devoted to physical and chemical methods included papers describing gas chromatography, spectrophotometry, chomical extraction, and infra-red analysis. Further sessions treated dielectric, resistive and capacitance methods, as well as nuclear methods, nuclear magnetic resonance in particular. The papers described equipment, methods of calibration, and typical uses and presented data on aceuracy.

\section{Standards}

The sessions on humidity standards were of special interest to staff members of the National Bureau of Standards, several of whom presented papers on this subject, and in general to scientists needing accurate hygrometry devices. Two of the papers described for the first time the use of the gravimetric hygrometer in making humidity measurements to a degrec of accuracy suitable for the most demanding humidity calibrations. Other papers described pneumatic bridges developed at the National Bureau of Standards which make possiblo calibration-level hygrometric determinations as a function of the pressure differential across the bridge. Also of intorest in this area were papers discussing the use of fixed humidity points in hygrometer calibrations.

\section{Applications}

The sessions concerned with the application of humidity and moisture measurements included the topics of meteorology, agriculture, biology and medicine, air conditioning, humidification and de-humidification, environmental chambers and radio propagation and atmospheric refraction. In these sessions, particularly, scientists and engineers had an opportunity to learn about each other's measurement problems and to exchange information among widely separated fields and disciplines.

The part played by humidity in meteorological phenomena was covered in detail by the papers presented. The distribution of moisture in the atmosphere was discussed, and special tochniques reported for its determination in the stratosphere. A 'state-of-the-art' survey on the application of hygrometry to meteorology was also presented.

Humidity and moisture are important in agriculture in many ways. Examples discussed were storage of agricultural products, particularly grain, flour and tobacco; curing peanuts and tobacco; the physiological responses of dairy cattle to humidity; the moisture content of butter, dehydrated foods and dry milk; and the moisture content of soils and its influence on plant growth.

The session on biology and medicine included papers on the effects of humidity on man, plants and biological systems. Humidity affects personal comfort, and imposes a stress on those working in hot environments; when controlled it can be used in treating lung disorders, for example.

The papers presented concerning air-conditioning, humidity control, humidification, and de-humidification were of a highly practical and engineering nature. Typical of the problems discussed were air-conditioning calorimetry, moisture in small refrigerating systems, residential humidification, chomical de-humidification, moisture control in dry-cleaning solutions, monitoring moisture in sealed electronic modules, and humidity levels in environmental cabinets and chambers.

Propagation of radio signals, observations of missile trajectories, and monitoring atmospheric turbulence depend to a largo extent on the refractive index of the atmosphere which, in turn, is a function of the ambient vapour pressure. Rescarch in this area also was presented. A paper on the potential of radio refractometry for humidity investigations and one on the use of radio refractometers to measure water vapour turbulence were presented. Papers on the use of radio, optical and microwave techniques for humidity measurements also were delivered.

The papers presented at the symposium will be published by the Reinhold Publishing Corp., New York, and are expected to bccome available early next year.

\section{REPROCESSING FOR IRRADIATED FUELS}

A SYMPOSIUM on "Aqueous Reprocessing Chemistry for Irradiated Fuels" was held in Brussels during April 23-26, under the auspices of the European Nuclear Energy Agency of the Organization for European Cooperation and Development and of the European Company for Chemical Proccssing of Irradiated Fuels (Eurochemic).

The object of the conference was to compare the progress made by the European countries which participate in Eurochemic, with the status of work in the samo field in the United States and the United Kingdom. About half the twenty papers presented were concerned with research and devolopment work being carried out either at Mol, Belgium, or elsewhere in Europe for the Eurochemic plant which is under eonstruction at Mol. Other papers from French and Italian authors were related to possible new reprocessing plants in theso two countries. As descriptions have been published in recent years on the major reprocessing plants of the United States and the United Kingdom, contributions from these countries were largely limited to surveys of recent developments.

It is apparent that on the Continent, as elsewhere, a solution of tributylphosphate in a hydrocarbon diluent is 